\title{
New complex class 1 integron carrying an ISCR 1 element in Escherichia coli clinical isolates harbouring the bla $\mathrm{CMY}_{11}$ gene
}

Resistance to $\beta$-lactam antibiotics in Gram-negative bacteria is mainly mediated by the production of $\beta$-lactamases, which are divided into four major Ambler's molecular classes (A, B, C and D). In previous studies, we have demonstrated that CMY-11 from a virulent clinical strain is a plasmid-encoded extended-spectrum class $\mathrm{C}(\mathrm{AmpC}) \beta$-lactamase conferring resistance to cefoxitin and cefotetan, as well as to penicillins and oxyiminocephalosporins (Lee et al., 2002). We previously obtained 710 Escherichia coli clinical isolates from patients with various infections, 9 of which showed high levels of resistance to amoxicillin, amoxicillinclavulanic acid, cefalotin, cefoxitin and cefotetan, as well as to cefotaxime, ceftazidime and aztreonam (Kim et al., 2004). All nine E. coli clinical isolates produced CMY-11 (Kim et al., 2004). A $b l a_{\mathrm{CMY}-11}$ gene, responsible for this $\beta$ lactam resistance, was located on a $\sim 130 \mathrm{~kb}$ conjugative plasmid harboured by the nine clinical isolates and their transconjugants (Kim et al., 2004). Clonal and plasmid spread contributed to $b l a_{\mathrm{CMY}-11}$ dissemination in Korean clinical isolates of E. coli (Kim et al., 2004; Song et al., 2009). This study was carried out to investigate the genetic environment surrounding the $b l a_{\mathrm{CMY}-11}$ gene, which can play an essential role in the translocation of the gene from a chromosome (or plasmid) to the conjugative plasmid.

The BLASTN (basic local alignment search tool used against nucleotide sequence databases) program of the National Center for Biotechnology Information (http:// www.ncbi.nlm.nih.gov) was used for DNA sequence database searches of integron element genes and other genes. The primers for PCR amplification were designed by selecting consensus sequences based on multiple nucleotide alignments

The GenBank/EMBL/DDBJ accession number of the sequence of the complex class 1 integron determined in this work is FJ763641.
(CLUSTAL $\mathrm{W}$ program) of searched genes. PCR and DNA sequence analyses (using the primers shown in Table 1) of nine clinical isolates revealed that the $b l a_{\mathrm{CMY}-11}$ gene was located in a new complex class 1 integron within the conjugative plasmid (Fig. 1a). To characterize this integron, recombinant plasmids with overlapping fragments were obtained as follows. Long

and accurate (LA) PCR amplification was performed with specific primers (Table 1). The LA PCR products were ligated with the pCR2.1-TOPO cloning vector (Invitrogen). The ligation mixture (recombinant plasmids) was introduced into competent E. coli DH5 $\alpha$ cells (Invitrogen) by transformation; transformant selection was by kanamycin

Table 1. Primers used in this study

\begin{tabular}{|c|c|c|}
\hline Target gene & Primer $^{*}$ & Sequence \\
\hline \multirow[t]{5}{*}{ intI1 } & intIf-F & 5'-CTA CCT CTC ACT AGT GAG GGG CG-3' \\
\hline & intIf-R & 5'-ATG AAA ACC GCC ACT GCG C-3' \\
\hline & intI1-F & 5'-CCT CCC GCA CGA TGA TCG TGC-3' \\
\hline & intI1-R & 5'-TCC ACG CAT CGT CAG GCA TTG-3' \\
\hline & C11-1F-1 & 5'-AAT CCA GAT CCT TGA CCC GCA G-3' \\
\hline dfrA12 & $\mathrm{C} 11-1 \mathrm{~F}-2$ & 5'-CTT CTC CCA TGC TCA CGA AAC AG-3' \\
\hline orfF & C11-1F-3 & 5'-GGC TTA CCT CGC CCG TTA GAC AT-3' \\
\hline \multirow[t]{4}{*}{ aadA2a } & 2-int-1-F & 5'-AAG TTA GAC ATC ATG AGG GTA-3' \\
\hline & 2a-sul1-w2-F & 5'-AGT GAT CTT CTT TTT GTC CCA-3' \\
\hline & C11-1R-1 & $5^{\prime}$-TCT GAT CGG ACA GGG CGT CTA A-3' \\
\hline & C11-1R-2 & 5'-GCT TAG TGC ATC TAA CGC CGG AG-3' \\
\hline \multirow[t]{2}{*}{ qacEA1 } & qacE $\Delta 1-\mathrm{F}$ & 5'-GTT ATC GCA ATA GTT GGC G-3' \\
\hline & qacE $\Delta 1-\mathrm{R}$ & 5'-AGC TTT TGC CCA TGA AGC AAC C-3' \\
\hline \multirow[t]{4}{*}{ sull } & sulf-F & 5'-ATG GTG ACG GTG TTC GGC AT-3' \\
\hline & sulf-R & 5'-CTA GGC ATG ATC TAA CCC TCG GTC-3' \\
\hline & sull-F & 5'-GAT TTT TCT TG AGC CCC GC-3' \\
\hline & sul1-R & 5'-TGG ACC CAG ATC CTT TAC AGG-3' \\
\hline \multirow[t]{5}{*}{ ISCR1 } & orf513-1F & 5'-ATG TCG CTG GCA AGG AAC GC-3' \\
\hline & orf513-2R & 5'-TCA AAG AGA CGA CTC TGT GAT GGA TC-3' \\
\hline & orf513-3F & 5'-TGA CTC TTA TCC AAC GCT TTG GC-3' \\
\hline & orf513-4R & 5'-CTG GCC GAC TAA TGT AGC GAC AC-3' \\
\hline & 2-qac-w3-F & $5^{\prime}$-TGC TCA GCT TTC CTT TCC AGC TAC G-3' \\
\hline \multirow[t]{4}{*}{$b l a_{\mathrm{CMY}-11}$} & $\mathrm{C} 1-\mathrm{F}$ & 5'-GAG CAG ACC CTG TTC GAG AT-3' \\
\hline & $\mathrm{C} 2-\mathrm{R}$ & 5'-GAT TGG CCA GCA TGA CGA TG-3' \\
\hline & 2-CMY-11-1-R & 5'-ATG AAT CCA CCT CCT CGG G-3' \\
\hline & 2-CMY-11-w2-R & 5'-AAT TCC CTC ACT CGT TTA CCG CTC-3' \\
\hline$y q g F$ & 2-CMY-11-w2-F & 5'-CTG CGT GAT GAC ATG GGG TTC CTT A-3' \\
\hline \multirow[t]{3}{*}{$y q g E$} & C11-4F-1 & 5'-CTA TGC TGA TGG CGA CAA TGG C-3' \\
\hline & 2-CMY-11-w3-F & 5'-GCT TGA GCT TGG TCA GCA TGG TGT C-3' \\
\hline & C11-4F-2 & 5'-GCA TGG CGA GCA GGA AGT GA-3' \\
\hline \multirow[t]{3}{*}{$g \operatorname{sh} B$} & 2-sul1-w3-R & $5^{\prime}$-ACC GAG TTC ATC TAC GCC ATC TAC A-3' \\
\hline & C11-4F-3 & 5'-GTT GGC GTC ATC CTC CTT CAT G-3' \\
\hline & C11-4R-2 & 5'-CCG AGC ACA AGG ACG TGA TCC-3' \\
\hline \multirow[t]{2}{*}{ orf 97, orf105 } & 2c-sul1-w2-R & 5'-CGC CCT ACA GCA TCA ACA CCC T-3' \\
\hline & C11-4R-1 & $5^{\prime}$-GCC CGT ACC GTG CAG GAA G-3' \\
\hline
\end{tabular}

${ }^{\star}$ Orientation of each primer: F, forward; R, reverse. 
(a)

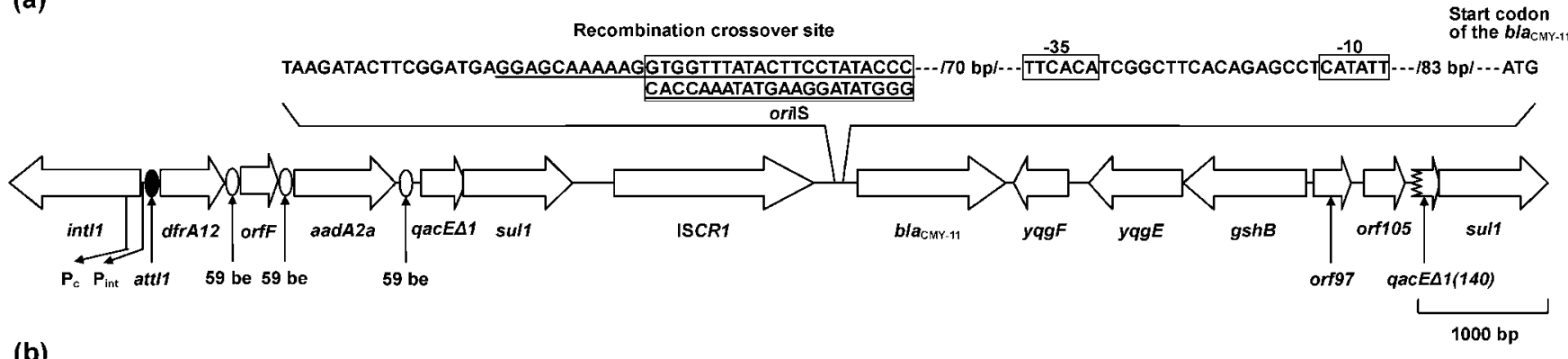

(b)

pTO21-33D

pTO21-33E

pTO21-33F

Fig. 1. (a) Schematic representation of the backbone structure of the complex class 1 integron harbouring novel genes on a $130 \mathrm{~kb}$ conjugative plasmid. White arrows, ORFs; white ovals, 59 base element (be); black oval, att/1 recombination site. $P_{\mathrm{c}}$ (5'-TGGACATAAGCCTGTTCGGTTCGTAAACT-3') and $P_{\text {int }}$ (5'-AGTCTATGCCTCGGGCATCCAAGCAGCAA-3') are promoters for cassette genes and integrase-encoding gene (int/1), respectively. The -35 and -10 motifs of the bla gene promoter are indicated by boxes. The RCS is underlined. oriS (the initiation site of ISCR1 transposition) is indicated by a box and underlined. qacEA1(140) shows a 140 bp deletion at the $5^{\prime}$ end of qacEA1, and the remainder of the two genes are identical. (b) Three subclones that were used for sequencing.

(50 $\mu \mathrm{g} \mathrm{ml}^{-1}$; Sigma-Aldrich). In Fig. 1(b), the recombinant plasmids are pTO21-33 D (4050 bp, a recombinant plasmid carrying the sull-type integron), pTO21-33E (3755 bp, a recombinant plasmid carrying a region from within sull to within bla $\left.a_{\mathrm{CMY}-11}\right)$ and pTO21-33F [5036 bp, a recombinant plasmid carrying a region from within $b l a_{\mathrm{CMY}-11}$ to qacEd1(140)/ sul1]. Consequently, the plasmids covered, together, a 11839 bp region containing $b l a_{\mathrm{CMY}-11}$. To avoid repetition of information about the integron, only the first characterized sequence of this integron was submitted to the GenBank database.

A sul1-type class 1 integron, containing $d f r A 12$, orfF and aadA2a gene cassettes, was identified upstream of $b l a_{\mathrm{CMY}-11}$ and ended with a $3^{\prime}$ conserved segment ( $3^{\prime}$-CS) (qacEA1-sul1). The sequence past the end of the 3'-CS was almost identical to the $2.15 \mathrm{~kb}$ common regions for In 6 of $\mathrm{pSa}$ (Stokes et al., 1993) and for integrons of pAr-32 (Sorum et al., 2003), pSAL-1 (Verdet et al., 2000), pAJE0508 (Bae et al., 2007), pCMXR1 (Doi et al., 2002) and pKO56 (Jeong et al., 2005). All common regions carried an ISCR1 element. Recently it has been suggested that the ISCR1 element is a member of an extended family of IS91-like elements that can transpose adjacent DNA sequences by a mechanism termed rolling-circle transposition and are responsible for the mobilization of many classes of antibiotic-resistance genes, including $b l a_{\mathrm{CMY}-9}, b l a_{\mathrm{DHA}-1}, b l a_{\mathrm{CTX}-\mathrm{M}-14}$, catA2 and qnr genes, but never bla $a_{\mathrm{CMY}-11}$ thus far (Toleman et al., 2006). A recombination cross-over site (RCS) (33 bp DNA sequence containing oriIS) at which insertion of resistance genes into the complex class 1 integron containing ISCR 1 takes place was observed downstream of ISCR1 (Bennett, 2008). A 182 bp region that was identified between the RCS and the start codon of the $b l a_{\mathrm{CMY}-11}$ gene had no identity to any known nucleotide sequences. This unique region was first identified in the integron harbouring the $b l a_{\mathrm{CMY}-11}$ gene. Furthermore, the genetic environment surrounding the $3^{\prime}$ end of RCS revealed that, compared to the upstream sequence of $b l a_{\mathrm{CMY}-1}$ (GenBank accession no. X92508), the upstream sequence of $b l a_{\mathrm{CMY}-11}$ had an additional 18 bases. On the other hand, the upstream sequences of $b l a_{\mathrm{CMY}-9}$ (Doi et al., 2002) and bla ${ }_{\mathrm{CMY}-8}$ (Chen et al., 2007) lacked 50 bases compared with the upstream sequence of $b l a_{\mathrm{CMY}-1}$. These nucleotide sequence analyses of $b l a_{\mathrm{CMY}-1}, b l a_{\mathrm{CMY}-8}$, $b l a_{\mathrm{CMY}-9}$ and $b l a_{\mathrm{CMY}-11}$ genes indicate that there might have been transposition events mediated by the ISCR 1 element upstream of $b l a_{\mathrm{CMY}-11}$ in the past because of the different genetic environments surrounding the $3^{\prime}$ end of RCS in these genes. A published report suggested that this variation is indicative of past transposition events (Doi et al., 2002).

A unique gene array $(y q g F-y q g E-g s h B-$ orf97-orf105) was first identified between $b l a_{\mathrm{CMY}-11}$ and a duplicate [qacEA1(140)sull] of the $3^{\prime}$-CS (Fig. 1). The third ORF $(g s h)$ encoded a 316 amino acid protein, which shared $95 \%$ identity with the amino acid sequence of glutathione synthetase (GshB) of Aeromonas hydrophila (Seshadri et al., 2006). The nucleotide sequence identity of the $b l a_{\mathrm{CMY}-11}$ gene with the $b l a_{\text {AmpC }}$ gene (GenBank accession no. GQ152601) from Aeromonas punctata was $85 \%$, which suggests that this gene may have originated from the DNA of $A$. punctata. The functions of YqgF, YqgE, Orf97 and Orf105 are unknown.

When compared with nucleotide sequences of other complex class 1 integrons, the region (intI1-aadA2aqacEA1-sul1-ISCR1-RCS) in the new integron harbouring the $b l a_{\mathrm{CMY}-11}$ gene is significantly similar to those of In6 and of the integrons of pAr-32, pSAL-1 and pAJE0508 detected in Australia, Norway, France and South Korea, respectively. The region $\left(b l a_{\mathrm{CMY}-11-y q g F-y q g E}\right)$ between the 
RSC and $g s h B$ in the integron is very similar to those of integrons of pCMXR1 and pK29 (Chen et al., 2007) in Japan and Taiwan. The region [orf105-qacEA1(140)sull] in the new integron containing the $b l a_{\mathrm{CMY}-11}$ gene is identical to that of the integron of pKO56 in South Korea. These results suggest that the integron containing the $b l a_{\mathrm{CMY}-11}$ gene might be derived from these integrons identified predominantly in East Asia (especially South Korea and Japan). This work highlights the genetic environment of the $b l a_{\mathrm{CMY}-11}$ gene, which has been associated with a new complex class 1 integron bearing an ISCR 1 element for what is believed to be the first time.

\section{Acknowledgements}

This work was supported by research grants from the Korea Research Foundation (KRF2008-313-C00790) and the Driving Force Project for the Next Generation of Gyeonggi Provincial Government in Republic of Korea.

\section{Jae Seok Song, ${ }^{1 \dagger}$ Seon Ju Jang, ${ }^{1 \dagger}$ II Kwon Bae, ${ }^{2+}$ Hyun Ji Lee, ${ }^{1}$ Byeong Chul Jeong ${ }^{1}$ and Sang Hee Lee ${ }^{1}$}

${ }^{1}$ Drug Resistance Proteomics Laboratory, Department of Biological Sciences, Myongji University, San 38-2 Namdong, Yongin, Gyeonggido 449-728, Republic of Korea

${ }^{2}$ Research Institute for Antimicrobial Resistance, Kosin University College of Medicine, Busan, Republic of Korea
Correspondence: Sang Hee Lee (sangheelee@mju.ac.kr)

†Jae Seok Song, Seon Ju Jang and II Kwon Bae contributed equally to this work.

Bae, I. K., Lee, Y. N., Lee, W. G., Lee, S. H. \& Jeong, S. H. (2007). Novel complex class 1 integron bearing an ISCR1 element in an Escherichia coli isolate carrying the $b a_{\mathrm{CTX}-\mathrm{M}-14}$ gene. Antimicrob Agents Chemother 51, 3017-3019.

Bennett, P. M. (2008). Plasmid encoded antibiotic resistance: acquisition and transfer of antibiotic resistance genes in bacteria. Br J Pharmacol 153, S347-S357.

Chen, Y.-T., Lauderdale, T.-L., Liao, T.-L., Shiau, Y.-R., Shu, H.-Y., Wu, K.-M., Yan, J.-J., Su, I.-J. \& Tsai, S.-F. (2007). Sequencing and comparative genomic analysis of pK29, a 269-kilobase conjugative plasmid encoding CMY-8 and CTXM-3 $\beta$-lactamases in Klebsiella pneumoniae. Antimicrob Agents Chemother 51, 3004-3007.

Doi, Y., Shibata, N., Shibayama, K., Kamachi, K., Kurokawa, H., Yokoyama, K., Yagi, T. \& Arakawa, Y. (2002). Characterization of a novel plasmid-mediated cephalosporinase (CMY-9) and its genetic environment in an Escherichia coli clinical isolate. Antimicrob Agents Chemother 46, 2427-2434.

Jeong, J. Y., Yoon, H. J., Kim, E. S., Lee, Y., Choi, S. H., Kim, N. J., Woo, J. H. \& Kim, Y. S. (2005). Detection of $q n r$ in clinical isolates of Escherichia coli from Korea. Antimicrob Agents Chemother 49, 2522-2524.

Kim, J. Y., Song, J. S., Bak, S. H., Cho, Y. E., Kim, D. W., Jeong, S. H., Park, Y.-M., Lee, K. J. \& Lee, S. H. (2004). Dissemination of Escherichia coli producing AmpC-type $\beta$-lactamase (CMY-11) in Korea. Int J Antimicrob Agents 24, 320-326.

Lee, S. H., Kim, J. Y., Lee, G. S., Cheon, S. H., An, Y. J., Jeong, S. J. \& Lee, K. J. (2002).

Characterization of $b l a_{\mathrm{CMY}-11}$, an AmpC-type plasmid-mediated $\beta$-lactamase gene in a Korean clinical isolate of Escherichia coli. J Antimicrob Chemother 49, 269-273.

Seshadri, R., Joseph, S. W., Chopra, A. K., Sha, J., Shaw, J., Graf, J., Haft, D., Wu, M., Ren, $\mathrm{Q}$. \& other authors (2006). Genome sequence of Aeromonas hydrophila ATCC $7966^{\mathrm{T}}$ : jack of all trades. J Bacteriol 188, 8272-8282.

Song, W., Lee, H., Lee, K., Jeong, S. H., Bae, I. K., Kim, J. S. \& Kwak, H. S. (2009). CTX-M-14 and CTX-M-15 enzymes are the dominant type of extended-spectrum $\beta$-lactamase in clinical isolates of Escherichia coli from Korea. J Med Microbiol 58, 261-266.

Sorum, H., L'Abee-Lund, T. M., Solberg, A. \& Wold, A. (2003). Integron-containing IncU $R$ plasmids pRAS1 and pAr-32 from the fish pathogen Aeromonas salmonicida. Antimicrob Agents Chemother 47, 1285-1290.

Stokes, H. W., Tomaras, C., Parsons, Y. \& Hall, R. M. (1993). The partial 3 '-conserved segment duplications in the integrons In6 from pSa and In7 from pDGO100 have a common origin. Plasmid 30, 39-50.

Toleman, M. A., Bennett, P. M. \& Walsh, T. R. (2006). ISCR elements: novel gene-capturing systems of the 21st century? Microbiol Mol Biol Rev 70, 296-316.

Verdet, C., Arlet, G., Barnaud, G., Lagrange, P. H. \& Philippon, A. (2000). A novel integron in Salmonella enterica serovar Enteritidis, carrying the $b l a_{\mathrm{DHA}-1}$ gene and its regulator gene $a m p R$, originated from Morganella morganii.

Antimicrob Agents Chemother 44, 222-225. 